\title{
VESTÍGIOS DE GLACIAÇÃO NAS SERRAS DO NW DE PORTUGAL CONTINENTAL: SÍNTESE DOS CONHECIMENTOS ATUAIS E PERSPETIVAS DE INVESTIGAÇÃO
}

\author{
TRACES OF GLACIATION IN THE NW MOUNTAINS OF PORTUGAL: \\ OVERVIEW OF CURRENT KNOWLEDGE AND PROSPECTS OF RESEARCH
}

\author{
António Vieira \\ Departamento de Geografia, Universidade do Minho \\ Campus de Azurém, Guimarães, CEP: 4804-533 - Portugal \\ Email: vieira@geografia.uminho.pt
}

António de Sousa Pedrosa

Instituto de Geografia, Universidade Federal da Uberlândia Av. João Naves de Ávila, 2121, Uberlândia, Minas Gerais, CEP: 38408-100 - Brasil

Email: aspedros@gmail.com

Lúcio Cunha

Departamento de Geografia, Universidade de Coimbra Largo da Porta Férrea, Coimbra, CEP: 3004-530 - Portugal Email: luciogeo@ci.uc.pt

António Bento-Gonçalves

Departamento de Geografia, Universidade do Minho Campus de Azurém, Guimarães, CEP: 4804-533 - Portugal

Email: bento@geografia.uminho.pt

\section{Informações sobre o Artigo}

Data de Recebimento: 03/05/2014

Data de Aprovação:

$01 / 11 / 2014$

\section{Palavras-chave:}

Glaciações; Wurm; NW de Portugal; Serra da Peneda; Serra do Gerês.

\section{Keywords:}

Glaciations; Wurm; NW Portugal; Serra da Peneda; Serra do Gerês.

\section{Resumo:}

O estudo da glaciação plistocénica no Noroeste de Portugal tem interessado a comunidade científica desde finais do século XIX. Das várias serras minhotas, apenas a do Gerês e da Peneda são consensualmente consideradas como áreas montanhosas afetadas pelas glaciações quaternárias, embora outras montanhas, apesar de mais baixas, pareçam evidenciar idênticos efeitos das glaciações. Apresenta-se neste trabalho uma síntese dos conhecimentos atuais e as perspetivas de investigação dos vestígios glaciares nas montanhas do NW de Portugal.

\section{Abstract:}

The study of Pleistocene glaciation in the Northwest of Portugal has interested the scientific community since the late nineteenth century. From all mountains of Minho, only the Peneda and Gerês are consensually regarded as mountain 
areas affected by Quaternary glaciations, although other mountainous areas appear to show identical effects of glaciation. Thus, this paper presents a synthesis of current knowledge and research perspectives of the remains of the glaciers in the mountains NW Portugal.

\section{1 - Introdução}

As montanhas do NW de Portugal situam-se no denominado Maciço Hespérico, cuja estrutura se mostra extremamente complexa em termos litológicos, estratigráficos e tectónicos. Inserem-se na denominada Zona Centro-Ibérica que se apresenta como um domínio bastante heterogéneo do orógeno Varisco, compreendendo áreas com diferentes graus de metamorfismo e abundantes intrusões de rochas granitóides (RIBEIRO et al., 1979).

A sequência latitudinal das serras de Arga, Peneda/ Gerês, Barroso, Cabreira, Alvão, Marão, Montemuro e Caramulo, estas duas últimas localizadas já a sul do Douro, representam, quer pela altitude que atinge, quer pela sua massa (DIAS, 1949), uma divisão natural que determina a mutação na identidade paisagística do norte e centro de Portugal. Este conjunto orográfico é responsável por uma transformação brusca do carácter atlântico das paisagens da área do Minho para a de Trás-os-Montes, refletindo a transição climática resultante da alteração do predomínio da influência marítima para a influência continental (DAVEAU, 1995).

À exceção da serra do Marão, composta fundamentalmente por xistos e quartzitos, os demais maciços possuem como suporte geológico rochas granitóides, cortadas profundamente por alinhamentos de fratura tardi-hercínicos ou alpinos (FEIO e BRITO, 1950), que condicionam o traçado dos principais rios da região e de alguns dos seus afluentes (REBELO, 1992).

Efetivamente, a tectónica fraturante é a principal explicação para a génese dessas serras. As linhas de água seguem frequentemente direções rígidas formando ângulos de $90^{\circ}$ e, apesar da sua elevada densidade, é ainda possível detetar níveis aplanados somitais como os do Gerês, a 1400 metros, da Peneda pelos 1100-1200 metros, da Cabreira pelos 900-1000 metros e da serra de Arga a 800 metros (FEIO, 1951a). A génese destes maciços montanhosos deve-se, assim, à ação das sucessivas fases orogénicas sobre o Maciço Hespérico, suporte morfo-estrutural da região norte de Portugal.

De fato, a norte do rio Douro a separação das serras minhotas do planalto Transmontano faz-se através das depressões associados à falha de direção tardi-hercínica (NNE-SSW) que define o desligamento de Verín-Penacova (FEIO, 1951B; BIROT, 1945; FERREIRA, 1991; PEDROSA, 1993; MARTINS, 2010) e que se prolonga para sul, estabelecendo o rígido limite oriental das serras de Montemuro (VIEIRA, 2008), Arada e Caramulo (CORDEIRO, 2004).

O relevo do Minho é tradicionalmente definido como "um amplo anfiteatro virado ao mar" (FEIO, 1951b; Figura 1), apresentando-se como uma quadrícula de blocos, separados por duas direções de fraturas: i) uma, ENE-WSW, que corresponde às direções dos principais vales minhotos (Minho, Lima, Cávado e Homem); ii) outra, entre N-S a NW-SE, em que as fraturas seguem as estruturas do soco hercínico ou cortam-nas com fraco ângulo (FEIO, DAVEAU, 2004). Segundo J. Cabral (1995), a existirem essas fraturas, elas corresponderiam "a descontinuidades com cisalhamento muito reduzido (...) ou a falhas de movimentação vertical, sem componente de deslocamento horizontal significativa”. Esta afirmação deve-se ao fato de elas não traduzirem uma perturbação assinalável dos contatos geológicos, se se tiver como referência a cartografia geológica disponível. Independentemente das possíveis e até muito prováveis deslocações verticais em falhas, com reflexos no relevo atual, a tectónica condiciona de uma forma indubitável a orientação da drenagem e o alargamento dos vales, como, de resto, foi salientado por M. Feio (1951a).

Igualmente de origem tectónica e envolvendo diversos tipos de rochas, embora com uma importância especial para os granitos, a serra de Montemuro, que se desenvolve entre o rio Douro e o troço médio do seu afluente rio Paiva, e a serra do Caramulo, entre o rio Vouga e a bacia de Mortágua, estão igualmente situadas a oeste do já referido acidente tardi-hercinico Verín-Penacova, e, como tal, a oeste dos grandes aplanamentos do centro do país. Ultrapassam os 1000 metros de altitude e, tal como as serras minhotas, também apresentam níveis aplanados de certa importância a diferentes altitudes, relacionados por um lado, com 


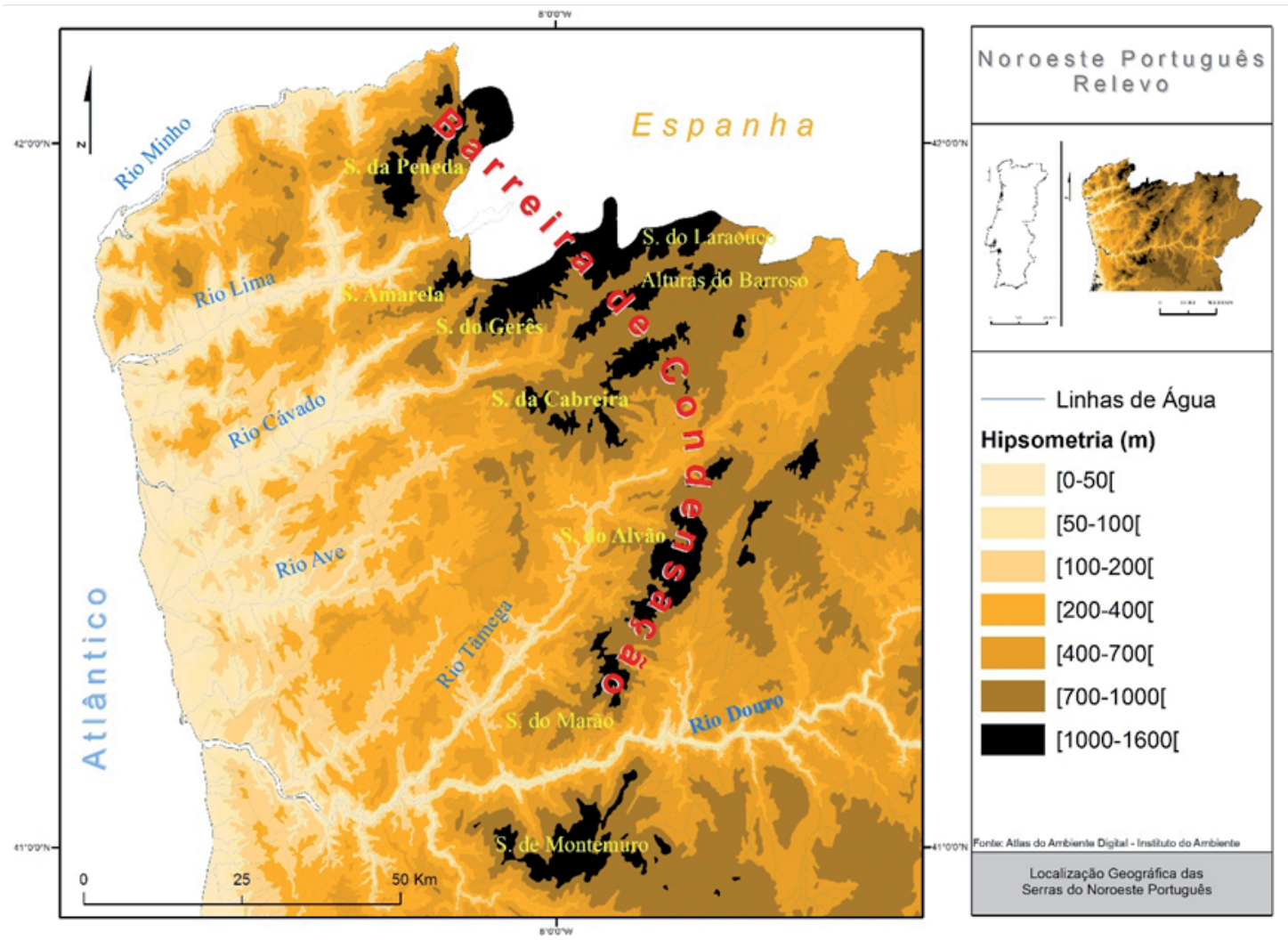

Figura 1 - Esboço de localização das serras do NW de Portugal

as deformações tectónicas a partir de um aplanamento geral e, por outro, com as características dos granitos (CORDEIRO, 1986; REBELO, 1992; VIEIRA 2001, 2003, 2008).

É importante salientar que a evolução das áreas montanhosas do NW de Portugal, durante o final do Quaternário, se relacionou fundamentalmente com a ação do frio, sendo este um dos principais responsáveis pela morfodinâmica nas vertentes (DAVEAU, 1973, 1978; REBELO, 1975; CORDEIRO, 1986, 1988, 2004; PEDROSA, 1993, 1994b, 2012; VIEIRA, 2008; PEDROSA et al., 2007; MARTINS, 2010).

De fato, os processos operantes durante o Wurm, aqueles que terão ficado mais marcados na morfologia atual, foram intensos e permitiram o desenvolvimento de formações superficiais que ainda hoje regularizam muitas das vertentes no norte de Portugal (PEDROSA, 1993, 1994a, 2012; PEDROSA, MARTINS, 2001, 2011). Assim, é indubitável que no final do Quaternário, nomeadamente durante o último período frio, tenham ocorrido processos morfogenéticos relacionados com o frio, responsáveis pela evolução dos vales e das suas vertentes, cujos vestígios podem ser de tipo glacial ou periglacial (PEDROSA, MARTINS, 2011).

Neste trabalho procurámos fazer uma síntese dos principais aspectos dos vestígios glaciares conhecidos nas serras do NW de Portugal Continental, ao mesmo tempo que se tenta indicar outro tipo de perspectivas de investigação, nomeadamente no que se refere à extensão para sul dos limites atualmente aceites para a glaciação.

\section{2 - Vestígios de glaciação nas serras do NW de Por- tugal Continental}

A existência de vestígios da ação de glaciares no território continental português constituiu, durante muito tempo, um tema controverso.

Ainda que a confirmação da glaciação na serra da Estrela tenha só ocorrido em 1929, por Herman Lautensach (1932), as primeiras observações da sua ocorrência remontam aos finais do século XIX, embora algumas possam ser hoje claramente erróneas e mesmo infundadas (RIBEIRO, 1866-67; CABRAL, 1881; DELGADO, 1895-98, apud FERREIRA, 1993).

No seu trabalho sobre a glaciação da serra da Estrela, publicado em português apenas em 1932, H. 
Lautensach definiu com grande rigor a extensão da glaciação na serra, mantendo-se muitas das suas conclusões hoje ainda válidas. Os trabalhos de Daveau (1971, 1986; DAVEAU et al., 1997) e mais recentemente de Vieira (2004) vieram aprofundar e pormenorizar o conhecimento sobre a glaciação na mais elevada serra de Portugal continental.

Se em relação à glaciação da serra da Estrela o consenso foi quase generalizado, já o mesmo não se pode dizer relativamente à glaciação das serras do noroeste de Portugal.

Lautensach (1945), inclusivamente, refere que "parece que a Serra da Estrela foi a única serra de Portugal coberta por geleiras na época glacial. Não se acham vestígios semelhantes nas serras portuguesas ao norte do Rio Douro, p. e. na Serra do Gerez, do Marão e do Larouco" (p. 20).

Só a partir dos anos 50 e 70 do século XX são apresentadas evidências da influência direta das glaciações na morfologia das serras do noroeste de Portugal.

Na realidade, diversos estudos demonstraram que os cimos das serras da Peneda e do Gerês conheceram durante o Quaternário uma glaciação significativa (GIRÃO, 1958; CARVALHO, NUNES, 1981; COUDÉ-GAUSSEN, 1981; MOREIRA, RAMOS, 1981; COUDÉ et al., 1983; VIDAL ROMANI et al., 1990; BRUM FERREIRA et al., 1992; VIDAL ROMANI, MOSQUERA, 1999; VIDAL ROMANI et al., 1999; FERREIRA et al., 1999).

Inicialmente Amorim Girão defendeu a existência de vestígios de glaciação na serra do Gerês, na área de Couce, afirmando que "os factos observados e as impressões colhidas não nos deixaram qualquer dúvida sobre o glaciarismo quaternário daquela serra...” (1958, p. 14).

Nos finais da década de 1970 Schmidt-Thome (1978) e Coudé-Gaussen (1978, 1979), ainda que com perspetivas distintas e apresentando conclusões sensivelmente diferentes, defendiam, igualmente, a existência de claros vestígios da glaciação nas serras do noroeste português. Segundo Coudé et al. (1983) a

localisation des glacês à eté fortement conditionné par le relief pré-existant, les larges vallés mures situées sous le vent des sommets ayant fonctionné comme pièges à neige alimentant des langues glaciaires, lorsque l'altitude de leur fond était proche de la limite des neiges ( $p$. 390).

Segundo os mesmos autores, na serra da Peneda o limite inferior das moreias situar-se-ia na ordem dos 600 metros.

Posteriormente, na sequência de investigações desenvolvidas por uma equipa composta por pesquisadores portugueses e espanhóis, Ferreira et al. (1992, p.134) afirmam a "existência, indiscutível de manifestações glaciárias, tanto na vertente minhota como na vertente galega” da serra do Gerês.

Segundo estes autores "as formas de erosão e de acumulação conservadas revelam uma glaciação fundamentalmente de circo e de vale, em que a espessura máxima das línguas glaciárias seria, numa hipótese de glaciação restrita, pelo menos da ordem dos 150m”. No entanto, acrescentam que "o estudo dos tills subglaciários sugere uma glaciação mais ampla, provavelmente com a formação de uma calote no planalto" (FERREIRA et al., 1992, p.134). Notam, ainda, que se verifica uma ausência de morfologia glacial típica, o que é sinal da pouca eficácia da ação dos glaciares, que se limitou à destruição e transporte dos mantos de alteração pré-glaciais e cuja dinâmica se encontrava condicionada em termos estruturais, mas fundamentalmente climática, manifestando-se uma clara assimetria NW-SE, com a acumulação preferencial das neves nas vertentes orientais mais frias e abrigadas dos ventos dominantes de oeste (FERREIRA et al., 1992).

S. Daveau $(1977,1986)$ avançou com a possibilidade da glaciação das serras minhotas se estender também à serra da Cabreira, a partir de um voo efetuado em 1977 com o intuito de identificar, nas serras do noroeste português, vestígios geomorfológicos de origem glacial. Após essas primeiras hipóteses de investigação, apresentou um trabalho em que demonstra que a glaciação se estendeu um pouco mais para sul das serras da Peneda e do Gerês, tendo atingido a serra da Cabreira onde devido a condições regionais e locais favoráveis "les hautes croupes de Cabreira (1262m) et de Toco (1138) ont bien fonctioné comme site d'acumulation de neiges persistants, avec transformation en neve et, localmement en glace sur les versants est e nord" (DAVEAU, DEVY-VARETA, 1985, p.77).

Este fato que aponta para áreas mais meridionais a influência glaciária no norte de Portugal poderia ser expli- 
cado por uma forte descida latitudinal da frente polar que, por volta dos 20000 a $16000 \mathrm{BP}$, teria atingido latitudes inferiores a $40^{\circ} \mathrm{N}$, ou seja, localizar-se-ia, em termos médios, um pouco a sul da cidade de Lisboa (CARVALHO, 1983).

Alguns trabalhos mais recentes vieram confirmar a existência de vestígios glaciares na serra da Cabreira que passam essencialmente por circos glaciares das vertentes norte e este do Toco, pelas rochas estriadas e calhaus boleados nas Azevedas, pelo ferrolho e pelas moreias laterais nos Gaviões e, também, pelos depósitos heterométricos a jusante das unidades de Soutinho e dos Gaviões (PEREIRA, BENTO GONÇALVES, 2001; VIEIRA et al., 2005).

\section{3 - A problemática da extensão da glaciação nas serras do NW de Portugal}

Investigações atuais desenvolvidas na serra da Peneda, quer na área das Brandas de Gorbelas e da Junqueira (PEREIRA et al., 2009), quer na área do alto vale do Rio Vez (SANTOS et al., 2013), próximas dos sectores mais elevados da serra da Peneda, permitiram a observação de depósitos sedimentares associados a estruturas tipicamente subglaciais, exigindo aplicação de metodologias de análise sedimentológica capazes de extrair novas indicações sobre os processos glaciais aqui ocorridos.

Pereira et al. (2009) procederam à análise de dois depósitos com recurso a análise sedimentológica (análise granulométrica e análise de lâminas através de lupa e microscópio petrográfico) no setor de GorbelasJunqueira, constatando tratar-se de depósitos típicos de ambiente subglacial, correspondendo a um till de alojamento em ambos os casos, localizados a cerca de 900 metros de altitude.

No vale glaciário do Alto Vez (Figura 2), a análise de dois depósitos morénicos localizados no setor terminal do mesmo, a cerca de 920 metros de altitude, realizada por Santos et al. (2013) com base em till fabric e análise granulométrica, confirmou tratar-se de dois tipos de till glaciais: till de alojamento depositado durante uma fase de avanço glacial; tills de fusão supraglaciais depositados durante fases de estabilidade e recuo glacial (Figura 3).

Para além da confirmação da ação glacial, já demonstrada pela presença de moreias, blocos erráticos e demais formas de desgaste e acumulação glacial, estes resultados permitem detalhar quer o espaço, quer os processos atuantes e, esperamos que também, os tempos da glaciação nas serras da Peneda-Gerês.

A identificação de depósitos típicos de ambiente subglacial (till de alojamento) vêm confirmar a dinâmica glacial nesta serra, colocando, no entanto, em questão os limites anteriormente estabelecidos para a área diretamente afetada pela glaciação, obrigando ao aprofundamento da investigação no sentido da sua reavaliação e concreta delimitação.

No que diz respeito às serras mais meridionais (Alvão, Marão, Montemuro e Caramulo), apesar da

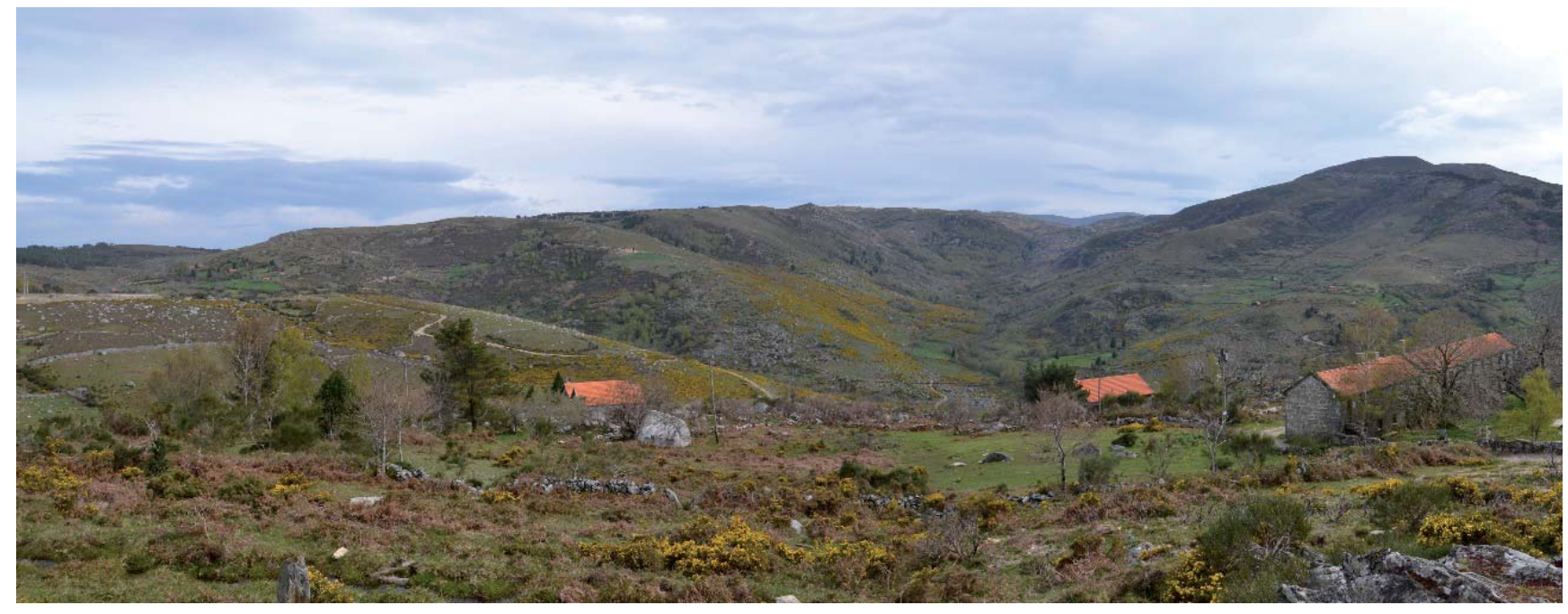

Figura 2 - Vale glaciário do Alto Vez. Reparar em primeiro plano no elevado número de blocos erráticos, graníticos, sobre os metassedimentos paleozoicos (xistos pelíticos). No setor central o vale glaciar do Alto Vez. 


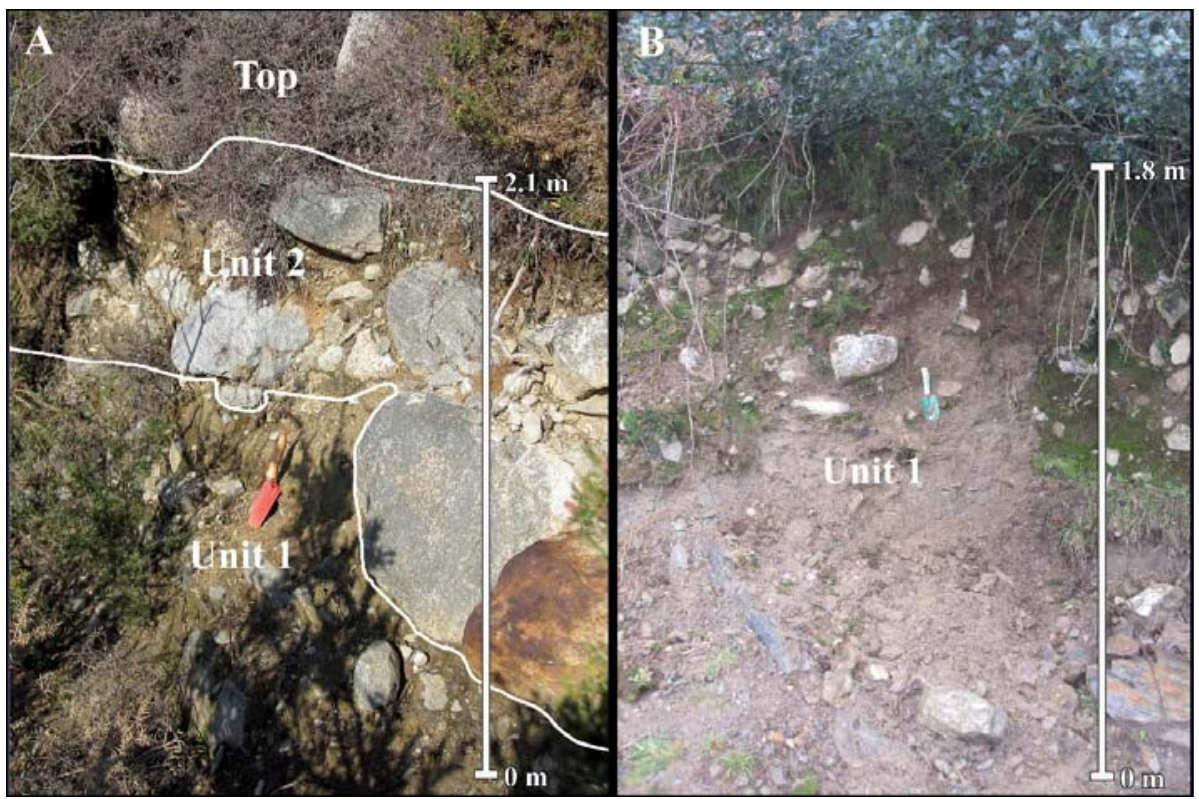

Figura 3 - Moreias laterais do vale glacial do Alto Vez.

ausência de vestígios claros da ação de glaciação, há indícios geomorfológicos da ação do gelo e do frio na modelação das vertentes, em ambiente se não verdadeiramente periglacial, pelo menos em ambiente crionival. Pedrosa (1993) aponta, nas serras do Alvão e Marão a existência de algumas formas que se podem relacionar com um clima glaciar atenuado como, por exemplo, a existência de nichos de nivação nas áreas de maior altitude. Num trabalho mais recente, Pedrosa (2012) coloca como hipótese a existência de alguns depósitos de fundo de vale que se encontram datados como anteriores a 28000BP como possíveis depósitos relacionados com a dinâmica glaciar (Figura 4).

Esta última hipótese traria a existência de uma glaciação, naturalmente com caraterísticas muito atenuadas, para latitudes na ordem dos $41^{\circ}$ de latitude, nas serras do NW de Portugal. É, no entanto, necessário aprofundar os trabalhos de campo e os estudos de análise laboratorial de modo a confirmar ou não esta hipótese de trabalho.

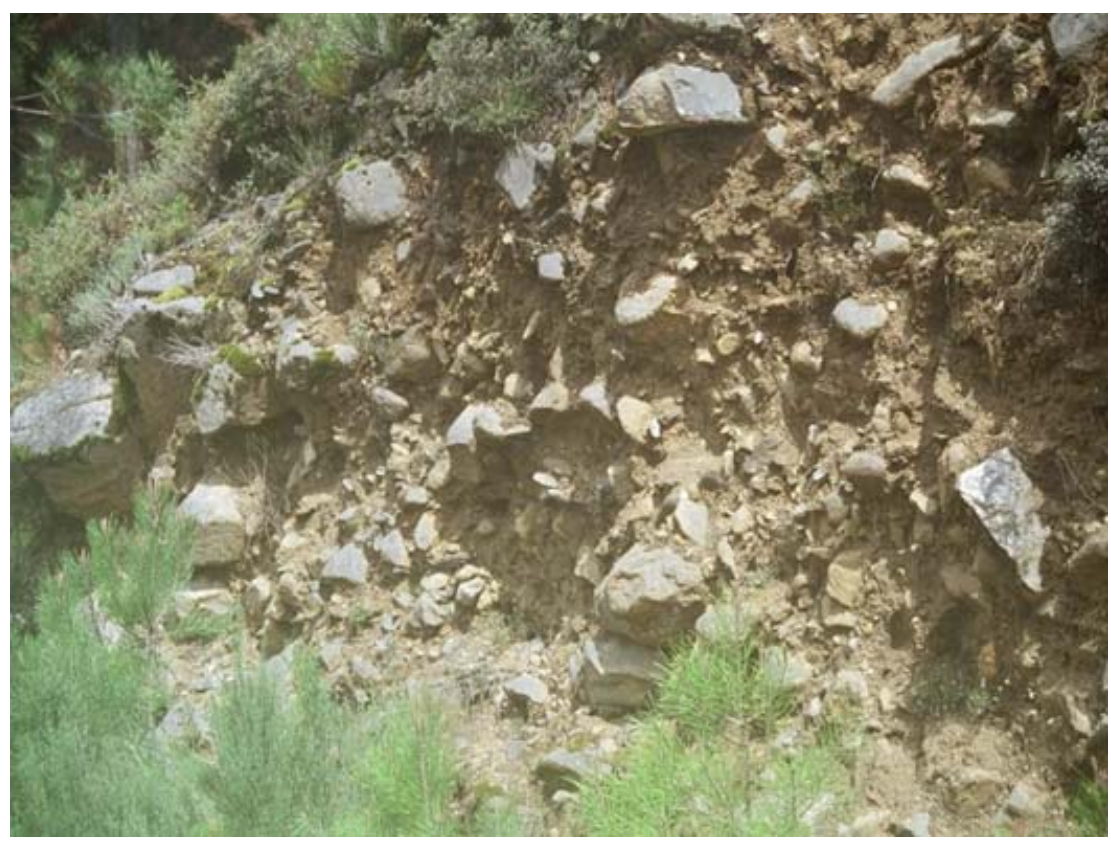

Figura 4 - Fácies inferior da formação de Muas onde se observam as suas características heterométricas, que poderão corresponder a um depósito de tipo glacial. 


\section{4 - Conclusão: perspetivas de investigação}

Podemos concluir que o último período frio quaternário foi responsável pela ocorrência de glaciares em Portugal. Este fato está bem testemunhado na serra da Estrela localizada na cordilheira central, mas também não existem dúvidas que a glaciação terá afetado as montanhas do NW português, de altitudes mais baixas e muito próximas do oceano, mas em que a corrente fria prolongada para sul durante o Würm, teria contribuído para o seu desenvolvimento. Assim, estudos recentes vieram comprovar a existência de glaciares nas serras do Gerês, Peneda e Cabreira, mostrando cada vez mais a importância da sua extensão. Os vestígios são diversos salientando-se como mais importantes circos glaciais, vales glaciais, diversos tipos de arcos e faixas morénicas, tills, blocos erráticos, entre outros.

Começa a colocar-se como hipótese a ocorrência de alguns vestígios mais atenuados em serras localizadas a sul das referidas como, por exemplo o Marão e o Alvão. Esta hipótese viria estender ainda mais a área afetada pelo glaciarismo nas serras do NW de Portugal.

Pensamos, deste modo, que se torna importante aprofundar os trabalhos nestas serras de modo a que:

i) se determine com precisão o tipo de vestígios relacionados com a ação do glaciarismo em Portugal;

ii) se compreenda a extensão dos fenómenos glaciares no norte de Portugal e se avalie a sua importância na dinâmica de evolução dos vales e das suas vertentes;

iii) se entenda a evolução climática do Quaternário final em Portugal e, deste modo, contribuir para a perceção da importância que os fenómenos climáticos podem deter em termos de consequências geoambientais e, particularmente, na construção das formas de relevo.

\section{Nota:}

Os autores António Vieira, Lúcio Cunha e António Bento-Gonçalves gostariam de prestar homenagem ao amigo António Sousa Pedrosa, coautor deste artigo, Geógrafo e Professor da Universidade do Porto (Portugal) e da Universidade Federal da Uberlândia (Brasil), que nos deixou prematuramente e que, connosco, partilhou inúmeros momentos de alegria.

\section{Referências Bibliográficas}

BIROT, P. Sur la morphologie de Trás-os-Montes. Bull. de l’Assoc. de Geog. Français, 1945, n. 173-174, p. 108-120.

CABRAL, J. Neotectónica em Portugal Continental. Memórias do Inst. Geol. Min., 31, Lisboa, 1995, 265 p.

CARVALHO, G. S. Consequências do frio durante o Quaternário na faixa litoral do Minho (Portugal), Cuad. Lab. Xeol. de Laxe, 5, 1983, p. 365-380.

CARVALHO, G. S., NUNES, J. L. A problemática dos índices glaciários quaternários nas serras do Gerês e Peneda. Cuad. Lab. Xeol. de Laxe, 2, A Coruña, 1981, p. 289-295.

CORDEIRO, A. R. Nota preliminar sobre as formas e formações periglaciares na Serra da Freita, Cadernos de Geografia, 5, Coimbra, 1986, p. 161-172.

CORDEIRO, A. R. Evolução das vertentes da Serra da Freita no Quaternário recente, Cadernos de Geografia, 7, Coimbra, 1988, p. 87-133.

CORDEIRO, A. R. Dinâmicas de vertentes em Montanhas Ocidentais do Portugal Central. Diss. Doutoramento, FLUC, Coimbra, 2004, 562 p.

COUDÉ, A.; COUDÉ-GAUSSEN, G., DAVEAU, S. Nouvelles observations sur la glaciation des montagnes du Nord-Ouest du Portugal. Cuadernos do Laboratório Xeológico de Laxe, 5, Coruña, 1983, p. 381-393.

COUDÉ-GAUSSEN, G. Confirmation de l'existence d'une glaciation Wurmienne dans les montagnes du Nord-Ouest du Portugal. Compt. Rend. Somm. Soc. Géol. de France, 1, 1978, p. 34-37.

COudÉ-GAussen, G. Les Serras da Peneda et do Gerês (Minho-Portuga/). Formes et formations d'origine froide en milieu granitique. Thése Univ. Paris1, Paris, 1979, 607 p.

Coudé-Gaussen, G. Les Serras da Peneda et do Gerês. Étude géomorphologique, Mem. Centro Est. Geogr., Lisboa, 5, 1981, 255 p.

DAVEAU, S. La glaciation de la Serra da Estrela, Finisterra, 11 (VI), C.E.G., Lisboa 1971, p. 5-40.

DAVEAU, S. Quelques exemples d'évolution quaternaire des versants au Portugal, Finisterra, 15 (VIII), C.E.G., Lisboa 1973, p. 5-47.

DAVEAU, S. Um exemplo de aplicação da teledetecção à investigação geográfica. A glaciação quaternária das montanhas do Noroeste de Portugal, Finisterra, XII, 23, Lisboa, 1977, p. 
156-159.

DAVEAU, S. Le périglaciaire d'altitude au Portugal, Colloque sur le périglaciaire d'altitude du domaine méditerranéen et abords, Association Géographoque d'Álsace, Strasbourg, 1978, p. 63-78.

DAVEAU, S. L'époque glaciaire au Portugal. Problémes méthodologiques, Actas I Jornadas de estudo Norte de Portugal/Aquitânia, CENPA, Porto, 1986, p. 183-191.

DAVEAU, S. Portugal Geográfico, Edições João Sá e Costa, Lisboa, 1995, 221 p.

DAVEAU, S., DEVY-VARETA, N. Gélifraction, Nivation et Glaciation d'Abri de la Serra da Cabreira. Actas da 1. ${ }^{a}$ Reunião do Quaternário Ibérico, Vol. 1, Lisboa, 1985, p. 75-84.

DAVEAU, S.; FERREIRA, A. B.; FERREIRA, N.; VIEIRA, G. T. Novas observações sobre a glaciação da Serra da Estrela, Estudos do Quaternário, 1, 1997, p. 41-51.

DIAS, J. Minho, Trás-os-Montes, Haut-Douro, Congrés International de Géographie, Lisboa, 1949.

FEIO, M. Adepressão da Régua - Verin, Notas Geomorfológicas, vol. 1, IAC-CEG, Lisboa. 1951a.

FEIO, M. Reflexões sobre o relevo do Minho, Notas Geomorfológicas, Centro de Estudos Geográficos, Lisboa. 1951b.

FEIO, M. E DAVEAU, S. (Org.). O Relevo de Portugal. Grandes Unidades Regionais, Associação Portuguesa de Geomorfólogos, Coimbra, 2004, 151 p.

FEIO, M.; BRITO, R. S. Les vallées de fracture dans le modele granitique portugais, C.R. Cangrês Int. Geog., II, 1950, p. 254-262.

FERREIRA, A. B. Neotectonics in Northern Portugal. A Geomorphological approach. Zeitschrift für Geomorphologie N. F., Suppl. Bd 82, 1991, p. 73-85.

FERREIRA, A. B. Manifestações geomorfológicas glaciárias e periglaciárias em Portugal. O Quaternário em Portugal. Balanço e perspectivas, Colibri, Lisboa, 1993, p. 75-84.

FERREIRA, A. B.; VIDAL ROMANI, J. R.; ZÊZERE, J. L.; RODRIGUES, M. L. A Glaciação Plistocénica da Serra do Gerês. Vestígios geomorfológicos e sedimentológicos, Relatório n. ${ }^{\circ}$ 37, A.G.F.A., C. E. G., Lisboa, 1999, 150 p.

FERREIRA, A. B.; VIDAL-ROMANI, J. R.; VILAPLANA, J. M.; RODRIGUES, M. L; ZEZERE, J. L., MONGE, C. Formas e depósitos glaciários e periglaciários da Serra do Gerés-Xurés
(Portugal; Galiza). Levantamento cartográfico, Cuad. Lab. Xeol. de Laxe, 17, 1992, p. 121- 135.

GIRÃO, A. Glaciação Quaternária da Serra do Jurês, Boletim do Centro de Estudos Geográficos, Vol. II, 16 e 17, Coimbra, 1958, p. 13-22.

LAUTENSACH, H. Estudo dos glaciares da Serra da Estrela. Mem. Not., Public. Mus. Lab. Min. Geol. Univ. Coimbra, 6, 1932, 60 p. (tradução por J:CUSTÓDIO DE MORAIS, do artigo publicado em 1929).

LAUTENSACH, H. Portugal na época glacial. Publicações do Instituto Alemão da Universidade de Coimbra, Coimbra, 1945.

MARTINS, B. Conhecimento geomorfológico entre as bacias de Chaves e Telões: contributo para a definição de áreas de risco geomorfológico, dissertação de doutoramento em Geografia Física, Faculdade de Letras de Coimbra, Coimbra, 2010.

MOREIRA, A.; D. RAMOS, J. Vestígios de glaciação na serra da Peneda (Noroeste de Portugal), Comum. Serv. Geol. Portugal, t. 67, fase 1, Lisboa, 1981, p. 95-98.

PEDROSA, A. S. Serra do Marão: Estudo de geomorfologia, Dissertação de Doutoramento, Faculdade de Letras da Universidade do Porto, Porto, 1993.

PEDROSA, A. S. Contributo para o conhecimento da dinâmica geomorfológica das serras do Norte de Portugal. O exemplo da serra do Marão, Rurália, Arouca, 1994a, p. 69-90.

PEDROSA, A. S. O Periglaciar no Norte de Portugal: O estado actual dos conhecimentos, Periglaciarismo en la Península Ibérica, Canaria y Baleares, Granada, 1994b , p. 55 - 73.

PEDROSA, A. S. A Importância da Ação do Frio do Quaternário Final em Portugal e suas Implicações nas Morfodinâmicas de Vertente. Revista Brasileira de Geografia Física, v. 02, 2012, p. 421-447.

PEDROSA, A. S.; MARQUES, B. S.; MARTINS, B.; SOUSA, J. H. Quaternary evolution of the Serra do Marão and its consequences in the present dynamics, Territorium, Revista da Associação Portuguesa de Riscos, Prevenção e Segurança, n¹4, 2007, p. 33-43.

PEDROSA, A. S; MARTINS B. Os movimentos em massa e os depósitos de vertente em áreas metassedimentares: alguns exemplos no Norte de Portugal in Actas do II Seminário sobre Recursos Naturais, Ambiente e Ordenamento do Território, Vila Real, 2001, CO-161-169.

PEDROSA, A. S., MARTINS, B. As formações superficiais no 
Norte de Portugal e suas implicações nos processos erosivos actuais. Geografia Ensino \& Pesquisa (UFSM), v.15, 2011, p. $55-72$.

PEREIRA, P.; BENTO GONÇALVES, A. J. Vestiges of the quaternary glaciation in Cabreira mountain. Estudos do Quaternário, Revista da Associação Portuguesa para o Estudo do Quaternário, APEQ, 2001, p. 61-68.

PEREIRA, P., PEREIRA, D. \& CASINHAS, P. Novos dados sobre a glaciação no sector Gorbelas-Junqueira (Serra da Peneda). Publicações da Associação Portuguesa de Geomorfólogos, Volume VI, APGEOM, Braga, 2009, p. 101-106.

REBELO, F. Serras de Valongo: estudo de Geomorfologia, Suplementos de Biblos, 9, Coimbra, 1975.

REBELO, F. Relevo de Portugal - uma introdução, Inforgeo, Lisboa, 4, 1992, p. 17-35.

RIBEIRO, A.; ANTUNES, M. T.; FERREIRA, M. P.; ROCHA, R. B.; SOARES, A. F.; ZBYSZEWSKI, G.; ALMEIDA, F. M. de; CARVALHO, D. ; MONTEIRO, J. H. Introdution à la géologie du Portugal, Publ. Serv. Geol. Portugal, Lisboa, 1979, 114 p.

SANTOS, J.; CUNHA, L.; VIEIRA, A.; BENTO-GONÇALVES, A. Caracterização e génese das moreias plistocénicas do vale glaciário do Alto Vez, Serra da Penda, Noroeste de Portugal. Atas/Proceedings VI Congresso Nacional de Geomorfologia, Coimbra, 2013, p. 57-62.

SCHMIDT-THOMÉ, P. Nuevos testigos de una glaciación wurmiense extensa y de altura muy baja en el Noroeste de la Península Ibérica (Orense, España y Minho/Trás-os-Montes, Portugal, Cuad. Sem. Est. Cerám. Sargadelos, 27, 1978, p. 219-243.

VIDAL ROMANI, J. R., FERNANDEZ MOSQUERA, D. Cronología glaciar pleistocena de la Serra de Gerês (norte de
Portugal), Estudos do Quaternário, 2, APEQ, Lisboa, 1999, p. 57-64.

VIDAL ROMANI, J. R.; FERNANDEZ MOSQUERA, D.; MARTI, K.; BRUM FERREIRA, A. de. Nuevos datos para la cronologia glaciar pleistocena en el NW de la Península Ibérica. Cadernos Lab. Xeolóxico de Laxe, 24, Coruña, 1999, p. 7-29.

VIDAL-ROMANI, J. R. VILAPLANA, J. M., FERREIRA, A. B., ZEZERE, J. L. Los tills de la Serra de Gerés-Xurés y la glaciación pleistocena (Minho, Portugal-Ourense, Galicia), Cuaternario y Geomorfología, 4, 1990, p. 13-25.

VIEIRA, A. A Serra do Montemuro. Contributo da Geomorfologia para a análise da paisagem enquanto recurso turístico, Diss. Mestrado, Coimbra, 2001, 212 p.

VIEIRA, A. Alguns aspectos da paisagem da Serra de Montemuro. Formas de pormenor do modelado granítico, in Escola Superior de Educação da Guarda (Ed.), Livro de Homenagem a José Miguel Carreira Amarelo, Guarda, ESEG publicações, 2003, p. 193-211.

VIEIRA, A. Serra de Montemuro: dinâmicas geomorfológicas, evolução da paisagem e património natural. Diss. Doutoramento, FLUC, Coimbra, 2008, 689 p.

VIEIRA, A.; BENTO GONÇALVES, A.; ALMENDRA, R. Vestígios da glaciação da Serra da Cabreira - cartografia geomorfológica de pormenor com recurso a tecnologias de geoprocessamento, Actas do X Colóquio Ibérico de Geografia, APG/AEG, Univ. Évora, Évora (CD-Rom), 2005.

VIEIRA, G. T. Geomorfologia dos planaltos e altos vales da Serra da Estrela. Ambientes frios do Plistocénico Superior e dinâmica actual. Dissertação de Doutoramento em Geografia (área de especialização em Geografia Física), apres. à Universidade de Lisboa, 2004, 724p. + 1 mapa. 